\title{
Effect of different ovule isolation times on the embryo development of Campanula hybrids
}

\author{
A.-C. Röper ${ }^{1}$, H. Lütken ${ }^{1}$, J. N. Hegelund ${ }^{1}$, K. K. Petersen ${ }^{2}$, B. Christensen ${ }^{3}$ and R. Müller ${ }^{1}$
}

${ }^{1}$ Department of Plant and Environmental Sciences, Faculty of Science, University of Copenhagen, Denmark ${ }^{2}$ Department of Food Science, Faculty of Science and Technology, Aarhus University, Denmark

${ }^{3}$ AgroTech A/S, Institute for Agri Technology and Food Innovation, Denmark

\section{CONCLUSION}

- Ovule isolation time is an important factor for a successful embryo rescue

- Ovule isolation time affected both the number of germinating embryos and the rate of their development in vitro

- Successful interspecific hybridisation: here obtained hybrids in vitro might not be prevented through prefertilisation or postfertilisation barriers

\section{OBJECTIVES}

In this study cultivars of three Campanula species from southeastern

Europe have been selected:

- To develop new interspecific hybrids

- To investigate the number of ovules and their subsequent germination rates in vitro from intra- and interspecific hybrids

- To determine the optimal ovule harvest period after in vivo pollination

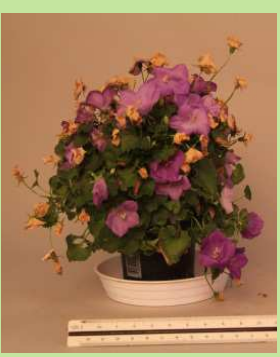

C. carpatica 'White'

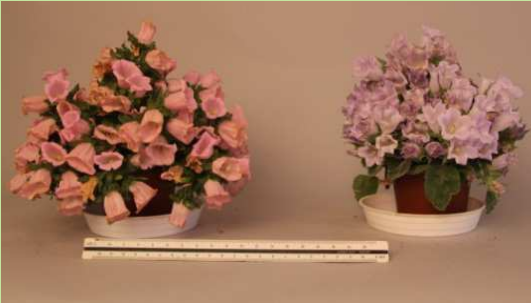

C. medium Pink' and C. formanekiana

\section{RESULTS}

\section{Isolation of ovules}

The number of isolated ovules varied between the intraspecific cross and the interspecific reciprocal crosses and depended on the ovule isolation time after pollination.

Table 1. The number of ovules: Self-pollination, intra- and interspecific hybridisation of selected Campanula species (from 15 pollinated flowers) isolated after different weeks after pollination

Number of ovules

\section{Cross}

\begin{tabular}{lcccc}
\cline { 2 - 5 } \multicolumn{1}{c}{ Cross } & 1 & 2 & 3 & 4 \\
& week & weeks & weeks & weeks \\
\hline C. carpatica White' (Intraspecific cross) & 372 & 2250 & 1 & 158 \\
C. medium 'Pink' (Self-pollination) & 75 & 25 & 324 & 550 \\
C. medium 'Pink' x C. formanekiana & 1 & 25 & 121 & 474 \\
C. formanekiana x C. medium Pink' & 50 & 270 & 350 & 3150 \\
\hline
\end{tabular}

$\rightarrow$ A later isolation time after pollination from the intraspecific cross did not result in an increased number of isolated ovules (Table 1)

$\rightarrow$ An increased number of ovules as an effect of a longer in vivo ovule development from self-pollination and the reciprocal interspecific crosses was observed (Table 1)

$\rightarrow$ The highest number of ovules was isolated when $C$. formanekiana was used as maternal parent

\section{Germination}

- Germination rate for ovules from $C$ formanekiana $\times$ C. medium Pink' increased from week 2 to week 3 (Figure 1)

- Ovules isolated 3 weeks after pollination germinated faster than after 2 weeks

Fig. 1. Germination, determined as percentage of ovules with a root longer than $1 \mathrm{~mm}$, for $C$. formanekiana $\times$. medium 'Pink' after ovule isolation 2 and 3 weeks after pollination

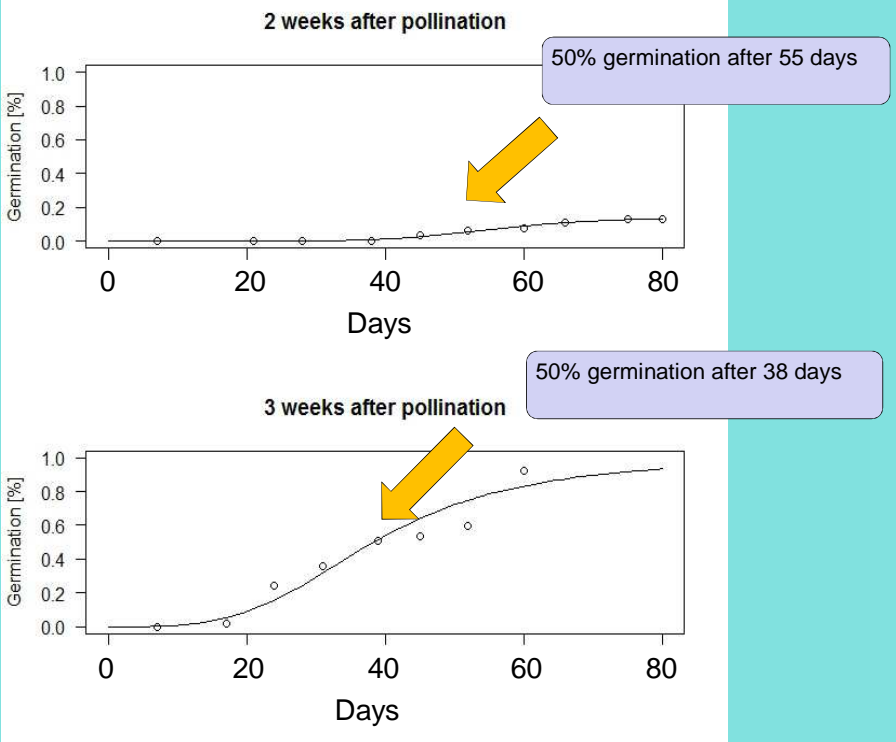

$\rightarrow$ The ovules collected 3 weeks after pollination showed a $50 \%$ germination after 38 days whereas a $50 \%$ germination after 2 weeks took 55 days (Figure 1 ).

$\rightarrow$ Ovule isolation 2 weeks after pollination resulted in approx. $14 \%$ germinated ovules in total, compared to a germination efficiency of $93 \%$ when ovules were isolated 3 weeks after pollination

\section{MATERIALS AND METHODS}

For the experiment two Campanula species with difficulties to hybridise were selected. Intraspecific cross and self-pollination were used as controls. The ovules were allowed to mature in vivo for 1-4 weeks after pollination, sterilised and placed on a half strength MS medium.

\section{Analyses}

Number of collectable ovules were recorded each week. The germination was monitored for 80 days and defined as emergence of the first visible root $(>1 \mathrm{~mm})$.

Statistical analysed as time to event data (Ritz et al., 2010) by using the statistic software program R (R Development Core Team, 2011).

\section{References}

Ritz, C., Pipper, C., Yndgaard, F., Fredlund, K. and Steinbrücken, G. 2010 Modelling flowering of plants using time-to-event methods. Europ. J. Agronomy 32: 155-161 R Development Core Team $2011 \mathrm{R}$ : A language and environment for statistical computing. R Foundation for Statistical Computing, Vienna, Austria. URL http://www.Rproject.org. ISBN 3-900051-07-0 